\title{
Quantifying Fire Risk for Telecommunications Network Integrity
}

\author{
EDWARD K. BUDNICK and LAWRENCE A. MCKENNA, JR. \\ Hughes Associates, Inc. \\ 3610 Commerce Drive, Suite 817 \\ Baltimore, Maryland 21227-1652, USA \\ JOHN M. WATTS, JR. \\ Fire Safety Institute \\ P.O. Box 674 \\ Middlebury, Vermont 05753, USA
}

\begin{abstract}
Several incidents in the last decade have shown the potential severity of a fire that causes interruption of a telecommunications network. Conformance with fire safety code requirements does not adequately address the susceptibility of critical equipment or service continuity. Initial evaluation of the problem revealed that significant conflicts existed among demands for technical accuracy, ease of use, and implementation cost. This led to development of a fire risk ranking method for the assessment of telecommunications network integrity. The approach uses a multiattribute evaluation model to determine the potential contributions to fire risk from individual fire safety parameters of a facility space. Weights for the identified parameters were developed systematically from fire safety policy, objectives, and strategies. Methods were constructed to grade the parameters from on-site survey information. Principles of Delphi, decision tables, Analytic Hierarchy Process (AHP), and other techniques of decision analysis were used in the development of parameter weights and grading methods. The scalar product of the parameter weights and grades produces a relative measure of the fire risk to integrity of a communications network.
\end{abstract}

KEY WORDS: Fire Risk Assessment, Telecommunications, Central Offices, Decision Analysis 


\section{INTRODUCTION}

Architecture and design of public telecommunications networks have historically required equipment controlling the network to be centrally located in buildings the industry calls "central offices" or "telephone exchanges". One consequence of this network architecture has been the concentration of risk: A fire or other disaster in a central office will have an enormous impact on the network.

A fire risk assessment tool for evaluating personnel safety and network integrity in an existing or proposed central office space has been developed [1]. The methodology is a numerical grading scheme similar in some respects to other methods developed for other types of occupancies $[2,3]$. This paper describes the network integrity aspects of assessing fire risk in telecommunications central office facilities.

\section{PROCEDURE}

Development of the assessment methodology consisted of four steps (1) identifying appropriate fire safety parameters, (2) calculating parameter weights, (3) establishing methods of grading parameters, and (4) specifying the procedure for calculating the fire risk value.

As each of these steps involves some subjective judgement, a project team was formed to represent a variety of expertise and responsibility. The team consisted of eight individuals primarily from within the telecommunications industry with skills in various aspects of fire safety engineering and fire risk management. For the initial steps of the procedure, the industry members of the team were used as a Delphi group to elicit subjective evaluations on decisionmaking levels and fire safety parameters. Steps (1) and (2) of the procedure were accomplished using the Edinburgh hierarchical approach in which a hierarchy is set up to help identify parameters and is then used to establish parameter weights $[4,5]$.

\section{HIERARCHY}

The methodology addresses elements of the facility environment that significantly influence fire risk. Elements were identified through a hierarchical process that linked them directly to a fire safety policy statement. The hierarchy developed for this methodology consisted of six levels as shown in table 1 . Levels one through four were used to calculate parameter weights and the last two levels were used to develop parameter grades.

\section{Fire Safety Policy}

Fire safety policy is a course or general plan to achieve security against fire and its effects. In the hierarchical approach it is defined as a vector of the relative importance of each of a set of fire safety objectives. For this project, fire safety policy was identified by the project team in terms of the objectives below. 
TABLE 1. Hierarchy of Fire Safety Decision Making Levels

\begin{tabular}{|c|l|l||}
\hline \hline LEVEL & \multicolumn{1}{|c|}{ NAME } & \multicolumn{1}{c||}{ DESCRIPTION } \\
\hline \hline 1 & POLICY & $\begin{array}{l}\text { Course or general plan to achieve security against fire } \\
\text { and its effects }\end{array}$ \\
\hline 2 & OBJECTIVES & Specific fire safety goals to be achieved \\
\hline 3 & STRATEGIES & $\begin{array}{l}\text { Independent fire safety aiternatives, each of which } \\
\text { contributes wholly or partly to the fulfillment of fire } \\
\text { safety objectives }\end{array}$ \\
\hline 4 & PARAMETERS & $\begin{array}{l}\text { Components of fire risk that are determinable by direct } \\
\text { or indirect measure or estimate }\end{array}$ \\
\hline 5 & SUBPARAMETERS & Intermediate components of a parameter \\
\hline 6 & SURVEY ITEMS & $\begin{array}{l}\text { Measurable features that serve as constituent parts of a } \\
\text { fire safety parameter or subparameter }\end{array}$ \\
\hline
\end{tabular}

\section{Fire Safety Objectives}

Four fire safety objectives were identified for the project as shown in table 2 . At this point in the project a decision was made to separate life safety and network integrity. The rational for this dichotomy was that life safety had a preexisting societal norm in the form of building and life safety codes while network integrity had no such guidelines. This paper focuses on network integrity as the most innovative aspect of the project.

TABLE 2. Fire Safety Objectives

\begin{tabular}{||l|l||}
\hline \multicolumn{1}{|c|}{ OBJECTIVE } & \multicolumn{1}{c|}{ DESCRIPTION } \\
\hline Provide Life Safety & $\begin{array}{l}\text { Protect personnel from all hazards associated with fire } \\
\text { insults. }\end{array}$ \\
\hline Prevent Equipment Loss & $\begin{array}{l}\text { Protect against loss or damage of telecommunications } \\
\text { equipment due to any fire or related insult. }\end{array}$ \\
\hline Prevent Service Interruption & $\begin{array}{l}\text { Protect equipment form fire and related insults that would } \\
\text { affect service. }\end{array}$ \\
\hline Prevent Facility Damage & $\begin{array}{l}\text { Prevent facility damage impact on people, service, and } \\
\text { equipment. }\end{array}$ \\
\hline
\end{tabular}

\section{Fire Safety Strategies}

At the third level of the hierarchy, the fire safety strategies selected include, prevent ignition, control fire growth, and manage/protect the exposed (people or things). Each of these strategies is an independent alternative in that each can contribute partially or totally in achieving the stated fire safety objectives. For example, to the extent that ignition prevention can be achieved, all four of the fire safety objectives are met. 
The fourth level in the hierarchy consists of the individual features in a facility that represent measurable components of the fire risk. Each feature, referred to as a fire safety parameter, contributes to achievement of the fire safety strategies, objectives, and policy. Seventeen parameters were identified that significantly influence fire risk in a central office space. For clarity, they are divided into the four groups; facility, contents, fire protection, and occupants, as shown in table 3 .

TABLE 3. Fire Safety Parameters

\begin{tabular}{|c|c|}
\hline \multirow{4}{*}{ FACILITY } & $\begin{array}{l}\text { Construction. Combustibility and fire endurance of load bearing structural } \\
\text { assemblies; number of floors }\end{array}$ \\
\hline & Height. Floor that space is on \\
\hline & $\begin{array}{l}\text { Compartmentation. Extent to which floor areas are divided by fire-resistive } \\
\text { walls and partitions }\end{array}$ \\
\hline & $\begin{array}{l}\text { Building Services. Electrical and mechanical equipment including HVAC, } \\
\text { power, and other utilities }\end{array}$ \\
\hline \multirow{4}{*}{ CONTENTS } & Cables. Amount and type of cables and cabling practices, e.g., mining \\
\hline & Equipment. Amount and type of switching equipment \\
\hline & $\begin{array}{l}\text { Ordinary Combustibles. Amount and type of ordinary and not otherwise } \\
\text { classified combustible contents, including interior finish }\end{array}$ \\
\hline & $\begin{array}{l}\text { Special Hazards. Building contents posing a higher than average degree of } \\
\text { hazard such as storage or use of flammable liquids or use of high-heat } \\
\text { producing appliances }\end{array}$ \\
\hline \multirow{7}{*}{$\begin{array}{l}\text { FIRE } \\
\text { PROTECTION }\end{array}$} & $\begin{array}{l}\text { Smoke Control. Equipment, systems, and protocols for limiting spread of } \\
\text { toxic and corrosive fire products }\end{array}$ \\
\hline & Alarm. Equipment and systems for transmitting an alarm of fire \\
\hline & Detection. Equipment and systems for detecting fires \\
\hline & $\begin{array}{l}\text { Fixed Suppression. Equipment and systems for automatic or semiautomatic } \\
\text { application of water, Halon, } \mathrm{CO}_{2} \text {, or similar agent, to a fire }\end{array}$ \\
\hline & $\begin{array}{l}\text { Fire Department. Capability and effectiveness of a fire department to } \\
\text { respond to an emergency fire situation and accomplish mitigation and rescue. }\end{array}$ \\
\hline & $\begin{array}{l}\text { Egress System. Number, capacity accessibility, and reliability of emergency } \\
\text { exits and areas of refuge }\end{array}$ \\
\hline & Power Down. Shutting off electrical service to de-energize equipment \\
\hline \multirow[t]{2}{*}{ OCCUPANTS } & $\begin{array}{l}\text { Personnel. Capability and effectiveness of occupants to react to an } \\
\text { emergency fire situation }\end{array}$ \\
\hline & Management. Fire safety policies, enforcement, and attitudes \\
\hline
\end{tabular}

\section{PARAMETER WEIGHTS}

To relate the relative importance of each fire safety parameter to the fire risk policy established as the top level in the hierarchy, the relative importance of the objectives, strategies, and individual parameters was determined.

A series of matrices was constructed, one for each adjoining pair of levels two, three, and four in the decision making hierarchy. Thus, in addition to the policy vector, a matrix of objectivesby-strategies and a matrix of strategies-by-parameters were formed. 
The cells in these matrices contained values representing the relative importance of the lower level items to achievement of the higher level items. For example, the strategies-by-parameters matrix contained the relative importance of each parameter to achievement of each strategy.

These importance values were determined through a Delphi exercise with references to available technical information and analytical methods. The cells were assigned a value from a Likert scale between zero and five. The three matrices were then combined using matrix multiplication. This produced a vector of the relative weights for each fire safety parameter in terms of its importance to fire safety policy.

\section{PARAMETER GRADES}

An essential feature of the methodology is the grading of fire safety parameters. Individual facilities will vary in the degree to which parameters exist or occur in a space. The parameter grades are a measure of these levels of danger or security. Usually a parameter grade is not directly measurable. This is especially true under conditions of surveying existing buildings with limited information readily available.

To simplify grading of parameters they were partitioned into measurable constituent parts. Usually these parts are directly measurable survey items. For several parameters, subparameters were also used. Decision tables were used to relate the survey items and subparameters to the fire safety parameters.

\section{Survey Items}

Survey items are the measurable building and space attributes that enable calculation of parameter grades. As such, they are an essential element of the method. Most parameter grades are determined from a list of several survey items. In some cases the survey items are used to determine values for sub-parameters that are in turn used to develop the parameter grades. In many circumstances, a survey item is a constituent part of more than one parameter.

The seventeen fire safety parameters were defined through a total of fifty-nine survey items. The survey items are determined from a field survey form that asks specific questions about each central office space. Seventy-nine questions were formulated to specify the survey items.

\section{Decision Tables}

A series of decision tables was developed to assign grades to each parameter. Some of these were quite simple, having only a few decision rules. For example, a simple decision table was developed to define a suppression damage threat as part of the "equipment" parameter. A suppression damage threat is the imperilment of essential equipment by the presence of fixed fire suppression systems. This is an important component since network integrity relies on the continuing post-fire functioning of vital equipment. 
Three attributes of fixed fire suppression are considered, type of agent, and for water systems, the method of operation, and type of valve. If there is no fixed suppression system, the agent type will be none $(\mathrm{N})$. Otherwise it is identified as water $(\mathrm{W})$, Halon $(\mathrm{H})$, or carbon dioxide (C). Water systems are further classified as to whether activation is automatic (A) or manual (M), i.e., requires some human action to operate and, for automatic activation, whether the valve is wet $(\mathrm{W})$ or preaction $(\mathrm{P})$. A wet valve system will expel water on the fire when a sprinkler operates. A pre-action system has no water in the pipes until actuation of an auxiliary fire detector charges the system and simultaneously alerts personnel.

As shown in the decision table (table 4), six decision rules represent all the possible outcomes of these three attributes. The resulting suppression damage threat will be zero (0), low (L) moderate $(\mathrm{M})$, or high $(\mathrm{H})$ as indicated for each decision rule.

TABLE 4. Decision Table for Suppression Damage Threat

\begin{tabular}{||c|c|c|c|c|c|c||}
\hline \multirow{2}{*}{ SURVEY ITEMS } & \multicolumn{7}{|c|}{ Decision Rules } \\
\cline { 2 - 8 } & 1 & 2 & 3 & 4 & 5 & 6 \\
\hline \hline Agent Type (N,W,H,C) & N & W & W & W & H & C \\
\hline Activation (A,M) & - & A & A & M & - & - \\
\hline Valve Type (W,P) & - & W & P & - & - & - \\
\hline \hline $\begin{array}{c}\text { Suppression Damage } \\
\text { Threat }\end{array}$ & 0 & H & M & M & 0 & L \\
\hline
\end{tabular}

For most parameters, the decision tables are long and complex. For example, the parameter "Cables" has 84 decision rules from which its grade is determined. In addition, some decision tables reference other decision tables allowing the parameter grading to be divided into a multilevel structure. One example is the "Equipment" parameter that has nine Decision Tables, one for each of six types of equipment and three to describe equipment vulnerability. Five other parameters also have multiple decision tables. Additional information on the use of decision tables for grading fire safety parameters is presented in a related paper [6].

\section{Sub-Parameters}

Sub-parameters are intermediate components of a parameter with a grade or assessment based on one or more survey items. In some cases, sub-parameters made identification of survey items easier, while in other cases, the parameter could be better expressed as a function of components associated with a number of survey items.

The relationship between a parameter and its sub-parameters was one of the most complex and challenging aspects of the project. In the simplest case, there was only a single sub-parameter, and the sub-parameter value is derived from a decision table, and that value is in turn input to the decision table for the "parent" parameter. In the most complex case, there are multiple sub-parameters that had interdependencies between themselves that needed to be analyzed before the parameter grading process could be developed. 
Several different processes were used to develop weights and/or values for each subparameter. The process varied by the complexity of the subparameters. For example, the parameter "Ordinary Combustibles" has only two subparameters, "Ignition" and "Fire Growth." Weights for these were estimated directly from experienced judgment of the project team. As suggested above, the most involved procedure of grading was for the "Equipment" parameter.

\section{Equipment Vulnerability}

The "equipment" parameter is the most intricate. It deals with six different iypes of equipment that may be present in a central office space; compuiers, batteries, other power, switching, transmission, and distributing frames. More than one type of equipment may be present and there may be multiple switching systems and distributing frames with different characteristics. The grading process for this parameter comprises thirteen distinct decision tables with 170 possible decision rules. The "equipment" parameter was broken down into three subparameters: "ignition," "fire growth," and "vulnerability."

Vulnerability of central office equipment to a fire incident is of critical importance in network integrity. Equipment vulnerability is a function of the direct effects of heat and smoke as well as the secondary effects of suppression agents. In turn, these secondary effects depend on the type of suppression system in place and the susceptibility of the equipment to damage from suppression agents. Figure 1 summarizes the process of deriving a grade for the subparameter "equipment vulnerability" from survey items associated with the parameters "equipment" and "fixed suppression".

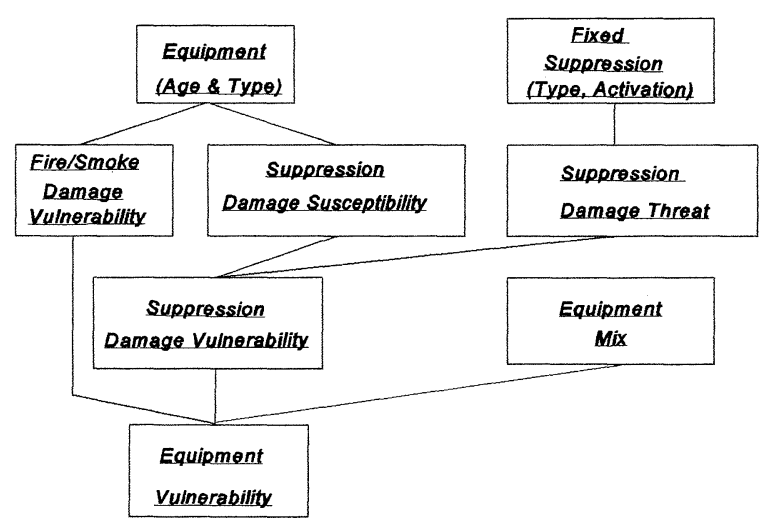

FIGURE 1. Equipment vulnerability sub-parameter.

A separate set of four decision tables was developed to produce a grade for equipment vulnerability. The first table generates grades for suppression damage susceptibility and fire/smoke damage vulnerability based on survey items that identify relevant characteristics of the equipment in the space, e.g., type and age. This table has thirty-two decision rules. 
The second table, shown as table 4 , considers survey items that characterize the suppression system in terms of its ability to cause secondary damage of equipment, e.g., type of agent, valve, and actuation. The output is the suppressicn damage threat. This threat together with the suppression damage susceptibility from the first decision table, produce a grade for suppression damage vulnerability in the third decision table (table 5).

TABLE 5. Decision Table for Suppression Damage Vulnerability

\begin{tabular}{|c|c|c|c|c|c|c|c|c|c|c|}
\hline \multirow[b]{2}{*}{ SUBPARAMETERS } & \multicolumn{10}{|c|}{ Decision Rules } \\
\hline & 1 & 2 & 3 & 4 & 5 & 6 & 7 & 8 & 9 & 10 \\
\hline Threat & 0 & L & $\mathbf{L}$ & L & $M$ & M & M & $\mathrm{H}$ & H & $\mathrm{H}$ \\
\hline Susceptibility & - & $L$ & M & $\mathrm{H}$ & L & M & $\mathrm{H}$ & L & M & $\mathrm{H}$ \\
\hline Vulnerability & 0 & L & L & $M$ & L & $M$ & $\mathrm{H}$ & $M$ & $\mathrm{H}$ & $\mathrm{H}$ \\
\hline
\end{tabular}

Where two different types of equipment are located in the same space, their response to fire may adversely affect each other. Such combinations of equipment are considered in determining a value for equipment mix. A final table with twenty-four decision rules combines equipment mix with suppression damage vulnerability and fire/smoke damage vulnerability to generate a grade for the sub-parameter, "Equipment Vulnerability."

\section{Analytic Hierarchy Process}

A more well-defined process of estimating sub-parameter weights is the Analytic Hierarchy Process (AHP). This technique is widely used in the field of decision analysis. It determines the relative importance of each sub-parameter by setting up a square matrix and making pairwise comparisons. Each possible pair of subparameters is examined and a subjective evaluation made as to which is more important (preferred) and to what extent. The degree of preference is assigned from a scale of one to nine. Weights of the relative importance of each subparameter can then be calculated from the matrix by any of several methods. The best-known and most supported by commercial software is the eigenvalue method [7]. In this project, calculations of sub-parameter weights were produced with the computer program HIPRE $3+$ [8].

As an example consider the parameter "Cables", which is defined as the amount and type of cable and cabling practices. In the decision tables that address this parameter, there are six subparameters: ignition sources, transfer processes, fuel (cable) ignitability, flame spread, corrosivity, and smoke production. The AHP process was used to derive weights for these sub-parameters. Weights of the relative importance of each sub-parameter were calculated from a matrix of pairwise preferences by the eigenvalue method. The parameter grade for the "Cables" parameter is then calculated as the scalar product of the sub-parameter weights and the sub-parameter values.

Potential for distortion and rank-reversal in applications of AHP has been discussed in the operations research and management science literature. The consensus seems to be that this is not a concern when the practical range of the attributes is known, as is the case here. 


\section{FIRE RISK VALUE}

Weighting and grading of each of the seventeen fire safety parameters produced a vector of parameter weights and a vector of parameter grades. A simple additive weighting model was used to combine these vectors to get an overall fire risk assessment value.

Additive weighting is a robust model widely used in multiattribute evaluation [9]. Each parameter weight is multiplied by its corresponding grade and the results summed to give the risk value, $V$, according to the following fornula:

$$
V=\sum_{i=1}^{17} w_{i} g_{i}
$$

where $w_{\mathrm{i}}$ is the weight of parameter $i$ and $g_{\mathrm{i}}$ is the grade of parameter $i$. Thus, the risk value is the scalar product of the parameter weights and the parameter grades that provides a quantitative measure of relative risk for the space being evaluated.

\section{SUMMARY}

A method has been developed for systematic assessment of the fire risk associated with spaces in central office telecommunications facilities. The method is design to be carried out manually or by integration into a computer-based program. Fire risk is measured and reported on an individual space basis and measures the risk for "network integrity" and "personnel safety."

The methodology integrates current technical knowledge and analytical methods with expert judgment to give the user a rational, consistent means to evaluate the relative fire risk in a central office space. Expert judgment was used to compensate for uncertainties in the state-ofthe-art in analytical methods used to calculate fire risk. These elements were integrated through a Delphi process involving members of the project group. The system is designed to permit modifications as technical knowledge is advanced in this area.

The basic method provides an evaluation of seventeen fire safety parameters determined to be of significant importance to fire risk in central office facilities. These parameters are graded using thirty-nine distinct decision tables containing 594 decision rules.

During development, the procedure was pilot tested at several different sites to establish that the results were plausible and did discriminate between acceptable and unacceptable risks. The decision rules have been programmed into a software package that is currently undergoing beta testing and will be used in a more extensive validation of the approach. 


\section{REFERENCES}

1. Parks, L.L., Kushler, B.D., Serapiglia, M.J., McKenna, L.A., Budnick, E.K., and Watts, J.M., "Fire Risk Assessment for Telecommunications Central Offices" (submitted to Fire Technology).

2. Watts, J.M., "Fire Risk Ranking", in SFPE Handbook of Fire Protection Engineering, ed. Philip J. DiNenno, 2nd ed., pp. 5-12 to 5-26, National Fire Protection Association, Quincy, MA, 1995.

3. Marchant, E.W., "A Cost-effective Approach to Fire Safety, Paper I - Points Scheme", International Fire Security and Safety Conference, 1984.

4. Stollard, P., "The Development of a Points Scheme to Assess Fire Safety in Hospitals", Fire Safety Journal, 7, 145-153, 1984.

5. Marchant, E.W., "Fire Safety Engineering - A Quantified Analysis", Fire Prevention, 210, 34-38, 1988.

6. Watts, J.M., Budnick, E.K., and Kushler, B.D. "Using Decision Tables to Quantify Fire Risk Parameters", Proceedings - International Conference on Fire Research and Engineering, Society of Fire Protection Engineers, Boston, 1995.

7. Saaty, T.L., Multicriteria Decision Making: The Analytic Hierarchy Process, RWS Publications, Pittsburgh, 1990.

8. Hamallainen, R.P., and Hannu, L., HIPRE 3+ User's Guide, TKK Offset, Espoo, Finland, 1992.

9. Keeny, R.L. and Raiffa, H., Decisions with Multiple Objectives, John Wiley, New York, 1976. 